\title{
"Dealloying" Phase Separation during Growth of Au on Ni(110)
}

Nielsen, L. Pleth; Besenbacher, Flemming; Stensgaard, I.; Lægsgaard, E.; Engdahl, C.; Stoltze, Per; Nørskov, Jens Kehlet

Published in:

Physical Review Letters

Link to article, DOI:

10.1103/PhysRevLett.74.1159

Publication date:

1995

Document Version

Publisher's PDF, also known as Version of record

Link back to DTU Orbit

Citation (APA):

Nielsen, L. P., Besenbacher, F., Stensgaard, I., Lægsgaard, E., Engdahl, C., Stoltze, P., \& Nørskov, J. K. (1995). "Dealloying" Phase Separation during Growth of Au on Ni(110). Physical Review Letters, 74(7), 11591162. https://doi.org/10.1103/PhysRevLett.74.1159

\section{General rights}

Copyright and moral rights for the publications made accessible in the public portal are retained by the authors and/or other copyright owners and it is a condition of accessing publications that users recognise and abide by the legal requirements associated with these rights.

- Users may download and print one copy of any publication from the public portal for the purpose of private study or research.

- You may not further distribute the material or use it for any profit-making activity or commercial gain

- You may freely distribute the URL identifying the publication in the public portal 


\title{
“Dealloying” Phase Separation during Growth of Au on Ni(110)
}

\author{
L. Pleth Nielsen, F. Besenbacher, I. Stensgaard, and E. Lægsgaard \\ Center for Atomic-Scale Materials Physics and Institute of Physics and Astronomy, \\ University of Aarhus, DK-8000 Aarhus C, Denmark \\ C. Engdahl, P. Stoltze, and J. K. Nørskov \\ Center for Atomic-Scale Materials Physics and Physics Department, \\ Technical University of Denmark, DK-2800 Lyngby, Denmark
}

(Received 16 September 1994)

\begin{abstract}
Combined scanning tunneling microscopy and ion-scattering studies have revealed a new "dealloying" phase transition during the growth of $\mathrm{Au}$ on $\mathrm{Ni}(110)$. The $\mathrm{Au}$ atoms, which initially alloy into the $\mathrm{Ni}(110)$ surface, phase separate into a vacancy-stabilized Au dimer-trimer chain structure at $\mathrm{Au}$ coverages larger than 0.4 monolayer. Using the effective-medium theory, we show that the resulting structure as well as the physical mechanism responsible for the phase transition are closely related to the surface stress induced by the substituted Au.

PACS numbers: 68.55.-a, 61.16.Ch, 61.50.Cj
\end{abstract}

Recently, scanning tunneling microscopy (STM) and total-energy calculations have revealed that metal-onmetal growth is much more complex than anticipated, based on simple surface free-energy arguments. It has become evident that surface alloying may be important in the initial phases of metal-on-metal growth [1-6]. Even for a system such as $\mathrm{Au}$ on $\mathrm{Ni}(110)$, which does not form bulk alloys, STM studies [7] have shown that deposited $\mathrm{Au}$ atoms replace surface $\mathrm{Ni}$ atoms forming a $\mathrm{Au}-\mathrm{Ni}$ surface alloy. The surplus $\mathrm{Ni}$ atoms nucleate into [110] elongated islands.

In this Letter, we present detailed in situ STM and Rutherford backscattering spectroscopy (RBS) investigations of room-temperature (RT) growth of $\mathrm{Au}$ on $\mathrm{Ni}(110)$, showing that as the $\mathrm{Au}$ coverage is increased above 0.4 monolayer (ML), a new "dealloying" phase transition in the topmost layer takes place. At a coverage of $0.4 \mathrm{ML} \mathrm{Au}$, we find that $\sim 0.16 \mathrm{ML}$ of the $\mathrm{Au}$ alloyed into the first $\mathrm{Ni}(110)$ layer abruptly "pops out" and nucleates into a new structure consisting of $\mathrm{Au}$ [001] oriented chains of alternating dimers and trimers. Combined total-energy calculations within the effectivemedium theory (EMT) and observations of the $\mathrm{Au} / \mathrm{Ni}$ surface coverages during the phase transition show that the $\mathrm{Au}$ chains nucleate on top of vacancies in the first surface layer. These vacancies arise due to the surface stress induced by the substituted $\mathrm{Au}$. The driving force behind the formation of the new structure and the nature of the phase transition will be discussed.

The experiments were performed with a high-stability UHV-STM described elsewhere [7,8]. Figure 1(a) is an STM topograph for a Au coverage of $0.38 \mathrm{ML}$, where a surface Au-Ni alloy is formed, and the replaced surface $\mathrm{Ni}$ atoms have nucleated into islands [7]. Increasing the Au coverage to above $0.4 \mathrm{ML}$ causes an abrupt phase transition to a structure where $\mathrm{Au}$ atoms form [001]directed chains, both on top of the islands and in between, as seen from Fig. 1(b). Atom-resolved STM images [Fig. 1(c)] reveal that they involve a zigzag pattern of dimers and trimers with apparent lengths of $2.5 \pm 0.2$ and $5.5 \pm 0.2 \AA$, respectively, and with an apparent height of $0.6 \pm 0.2 \AA$ above the alloyed $\mathrm{Ni}(110)$ surface.

From atom-resolved images [Fig. 1(c)] of the Au chains and the Ni substrate, we can correlate the number of $\mathrm{Au}$ atoms in the chains to the length of the chains. This is depicted in Fig. 2(a), and from the slope it is found that the one-dimensional $\mathrm{Au}$ density in the chains is $1.65 \pm 0.05$ atoms/[001] unit independent of the actual Au coverage.

The coherence of the Au chains is improved significantly by post-annealing the RT Au-exposed Ni surface to $700 \mathrm{~K}$ for $10 \mathrm{~min}$. This removes the many $\mathrm{Ni}$ islands creating large flat terraces with equispaced $\mathrm{Au}$ [001] chains [Fig. (d)]. Both the atomic structure of the chains and the surface alloying are unaffected by the annealing.

As more $\mathrm{Au}$ is deposited, new chains are nucleated, and the average chain-chain distance $d$ (in $\mathrm{Ni}[1 \overline{1} 0]$ units) decreases. Finally, $d$ converges to five [Fig. 1(e)] at a Au coverage of $0.93 \mathrm{ML}$. The structure is less coherent along the [001] direction, but the average periodicity is three [001] units, corresponding to a basic building block of one dimer connected to one trimer, that is, a $(5 \times 3)$ structure.

From the average one-dimensional Au coverage in the [001] chains, it is possible to calculate the $\mathrm{Au}$ coverage in the equispaced chains as $\theta_{\mathrm{Au}}^{\text {chain }}=1.65 / d$. Subtracting $\theta_{\mathrm{Au}}^{\text {chain }}$ from the total Au coverage, $\theta_{\mathrm{Au}}^{\text {tot }}$, as measured absolutely by RBS, gives the amount of $\mathrm{Au}$ alloyed into the first $\mathrm{Ni}$ layer as $\theta_{\mathrm{Au}}^{\text {alloy }}=\theta_{\mathrm{Au}}^{\text {tot }}-\theta_{\mathrm{Au}}^{\text {chain }}$. This quantity is shown in Fig. 2(b). A distinct discontinuity of $\sim 0.16 \mathrm{ML}$ in the amount of alloyed Au is clearly observed at $\theta_{\mathrm{Au}}^{\text {tot }}=0.4 \mathrm{ML}$, that is, $0.16 \mathrm{ML}$ of $\mathrm{Au}$ abruptly "pops out" of the alloyed surface layer and nucleates into [001]directed dimer-trimer Au chains, leaving behind 0.24 ML 


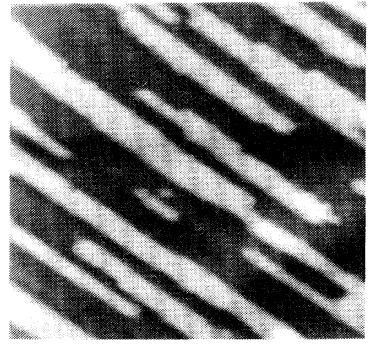

(a)

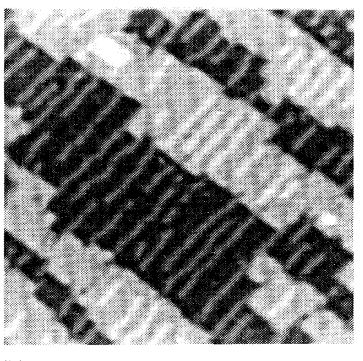

(b)

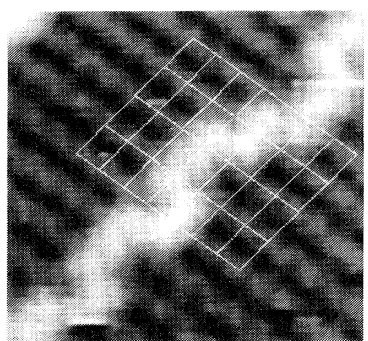

(c)

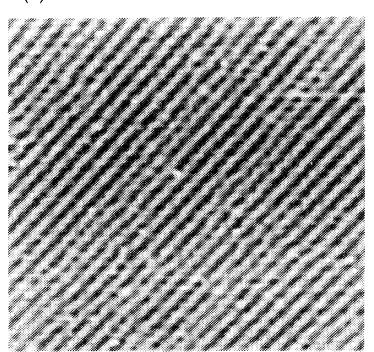

(e)

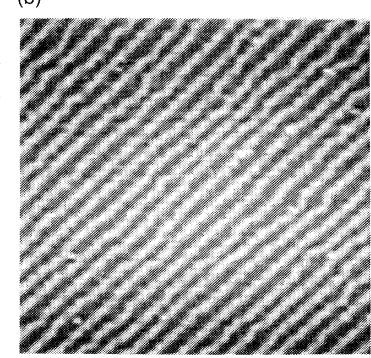

(d)

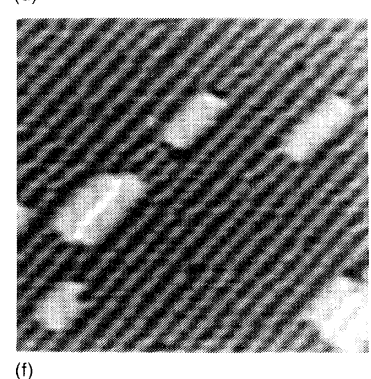

FIG. 1. (a) STM topographs showing (a) $\left(675 \times 731 \AA^{2}\right)$ the anisotropic growth of $\mathrm{Ni}$ islands $\left(\theta_{\mathrm{Au}}=0.38 \mathrm{ML}\right)$; (b) [001] directed $\mathrm{Au}$ chains $\left(480 \times 520 \AA^{2}\right.$ and $\left.\theta_{\mathrm{Au}}=0.52 \mathrm{ML}\right)$; (c) $\left(30 \times 30 \AA^{2}\right)$ the dimer-trimer chain structure $\left(\theta_{\mathrm{Au}}=\right.$ $0.45 \mathrm{ML})$, a $\mathrm{Ni}(1 \times 1)$ unit mesh is superimposed; (d) and (e) $\left(290 \times 315 \AA^{2}\right)$ of the chain structure at $\theta_{\mathrm{Au}}=0.7$ and $0.9 \mathrm{ML}$ (the distance between the chains is $d \sim 6.2$ and $d \sim 5$, respectively); (f) $\left(290 \times 315 \AA^{2}\right)$ a surface morphology like (d) after evaporation of an additional 0.1 ML Au.

alloyed into the $\mathrm{Ni}$ surface. As more $\mathrm{Au}$ is deposited, i.e., $\theta_{\mathrm{Au}}>0.4 \mathrm{ML}$, more chains are formed, but also additional $\mathrm{Au}$ is alloyed into the $\mathrm{Ni}$ surface implying that $\theta_{\mathrm{Au}}^{\text {alloy }}$ again increases. From Fig. $2(\mathrm{c})$ it is seen that the ratio between $\mathrm{Au}$ atoms in the chains and in the surface alloy is virtually constant, $\theta_{\mathrm{Au}}^{\text {chain }} / \theta_{\mathrm{Au}}^{\text {alloy }}=0.58 \pm 0.03$.

To unravel the atomic structure of the Au chains, we have performed approximate total-energy calculations, using EMT. The same method was successfully used to treat the surface alloying at lower coverages [7]. These calculations clearly rule out that the chain structure is a simple Au overlayer. The Au atoms in such an overlayer structure would gain energy by agglomerating into [110]directed $\mathrm{Au}$ islands where the $\mathrm{Au}$ atoms would have a larger coordination number. Instead, the calculations suggest that the Au dimer or trimer may be situated above a $\mathrm{Ni}$ vacancy or divacancy.
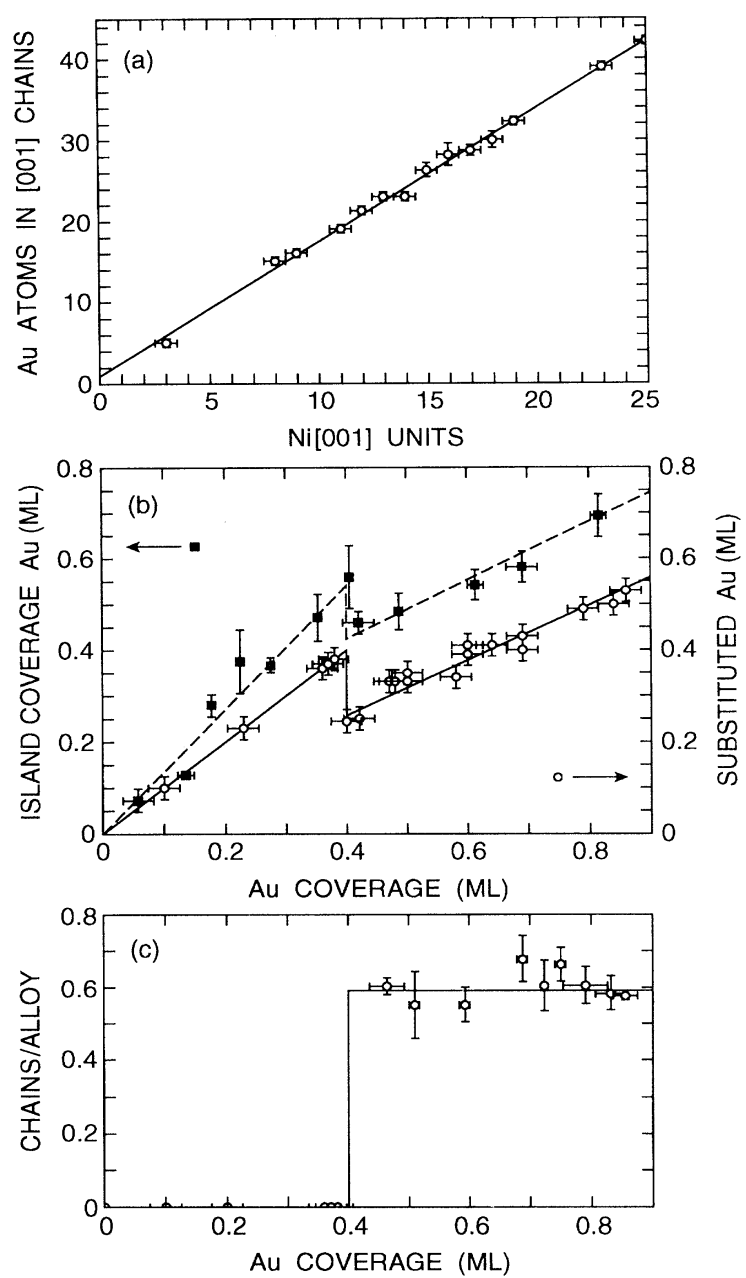

FIG. 2. (a) The number of $\mathrm{Au}$ atoms in the chains as a function of the number of underlying $\mathrm{Ni}[001]$ units. (b) The amount of substituted $\mathrm{Au}\left(\theta_{\mathrm{Au}}^{\text {alloy }}=\theta_{\mathrm{Au}}^{\mathrm{tot}}-\theta_{\mathrm{Au}}^{\text {chain }}\right)$ and the island coverage, determined from height distributions of large-area STM topographs, as a function of the total amount of evaporated $\mathrm{Au}\left(\theta_{\mathrm{Au}}^{\text {tot }}\right)$. (c) The chain/alloy ratio $\left(\theta_{\mathrm{Au}}^{\text {chain }} / \theta_{\mathrm{Au}}^{\text {alloy }}\right)$ versus $\theta_{\mathrm{Au}}^{\text {tot }}$.

The vacancy model is indeed supported by several experimental observations. Superimposing a $\mathrm{Ni}(110)$ unit mesh on Fig. 1(c), it is seen that the Au dimers and trimers are nucleating in atop positions in the [1 $1 \overline{1} 0]$ direction. Furthermore, at the phase transition $\left(\theta_{\mathrm{Au}}^{\mathrm{tot}}=\right.$ $0.4 \mathrm{ML}), 0.16 \mathrm{ML} \mathrm{Au}$ is dealloyed resulting in a reversed $\mathrm{Ni}$-mass transport from the islands back to the created $\mathrm{Ni}$ vacancies. However, from a detailed analysis of the area covered by the Ni islands as a function of the amount of evaporated Au [Fig. 2(b)], we find that the dealloying is correlated with a decrease in the area of the $\mathrm{Ni}$ islands by only $\sim 0.10 \mathrm{ML}$, implying that the new structure contains $\sim 0.06 \mathrm{ML}$ of vacancies. However, these vacancies are not directly observed in the STM images.

The model of a vacancy-stabilized Au dimer-trimer structure proposed above is further supported by measure- 
ments for which an additional $0.10 \mathrm{ML} \mathrm{Au}$ is evaporated onto a surface with a morphology like the one shown in Fig. 1(d). As seen from Fig. 1(f), the nucleation of extra $\mathrm{Au}$ chains is followed by the development of $\mathrm{Ni}$ islands on the surface. The decrease in the average distance between the $\mathrm{Au}$ chains corresponds to a $\Delta \theta_{\mathrm{Au}}^{\text {chain }}=$ $0.085 \mathrm{ML}$, and thus the amount of Au alloyed into the surface is increased by only $\Delta \theta_{\mathrm{Au}}^{\mathrm{alloy}}=0.100-0.085=$ $0.015 \mathrm{ML}$. However, the area of the islands in Fig. 1(f) corresponds to $\theta_{\text {is }}=0.07 \mathrm{ML}$. This verifies that an additional $\mathrm{Ni}$ mass transport, i.e., formation of $\mathrm{Ni}$ vacancies, is involved in the nucleation of the Au chains. Based on this model, we would expect an island coverage of $\theta_{\text {is }}=$ $(3 / 5) \Delta \theta_{\mathrm{Au}}^{\text {chain }}+\Delta \theta_{\mathrm{Au}}^{\text {alloy }} \sim 0.07$, in perfect agreement with the one observed.

In the following, we will address the EMT calculations in further detail. The calculated energy per substituted $\mathrm{Au}$ atom as a function of $\mathrm{Au}$ coverage is shown in Fig. 3(a). A clear quadratic dependence is seen, in accordance with simple elasticity theory [9]. The energy increases due to the compressive stress induced by the $\mathrm{Au}$ atoms substituted into the surface layer. When the
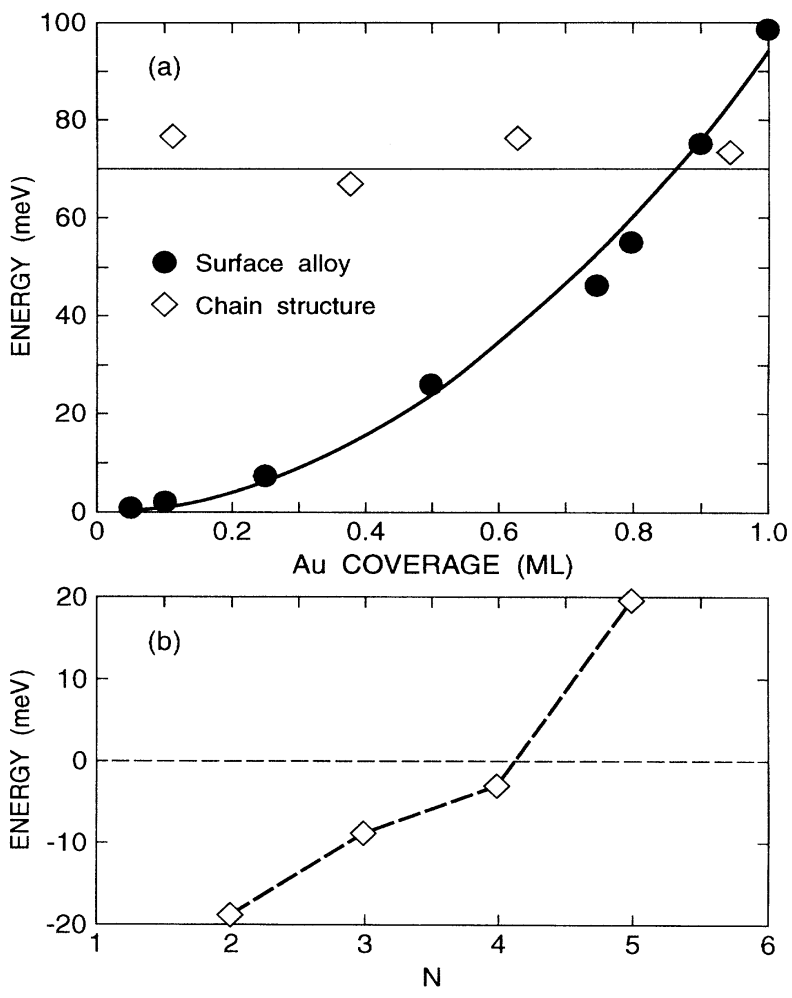

FIG. 3. (a) Energy as a function of coverage for Au substituted into the first surface layer (solid circles), and, for the chain structure of Fig. 4 (diamonds). (b) The interaction energy between a [001] chain with $N-1$ adjacent [001] columns of substituted $\mathrm{Au}$, and, a further ( $N$ th) substituted column. The energy is defined to be zero when the $N$ th column is far away from the chain. The energy corresponds to the $N$ th column occupying the nearest neighbor sites next to the other $N-1$ columns.
Au-induced compressive stress gets too high, it can be relieved through the formation of vacancies in the first Ni layer, and the vacancies can be stabilized through the adsorption of $\mathrm{Au}$ atoms on top of them. Single adsorbed $\mathrm{Au}$ atoms are very unstable due to the lack of nearest neighbors in the adsorbed layer, but if two Au atoms are placed along the [001] direction above one vacancy, they can have a reasonable interatomic distance and gain energy from their interatomic interactions. The same can be achieved if two vacancies are ordered along the [001] direction and three $\mathrm{Au}$ atoms are accommodated here. We therefore suggest that the observed structure originates from one where $\mathrm{Au}$ dimers and trimers share monomer and dimer [001] vacancies as shown in Fig. 4. The calculated structure has an interlayer distance between the surface Ni layer and the dimers and trimers of only $0.6 \AA$ in excellent agreement with the observed height of the $\mathrm{Au}$ chains.

The vacancy structure with adsorbed dimers and trimers is only stable when the compressive stress in the surface layer is large. This can be illustrated by the following model calculation: Imagine forming one $\mathrm{Au}$ dimer or trimer plus vacancy chain on a $\mathrm{Ni}(110)$ surface with a number of [001] columns of substituted $\mathrm{Au}$ atoms parallel to it, but far away from it (and each other),

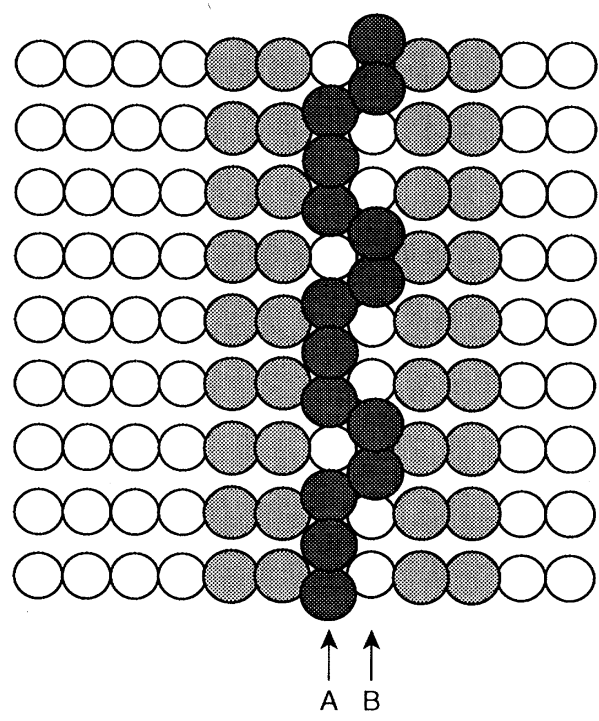

(a)

(b)

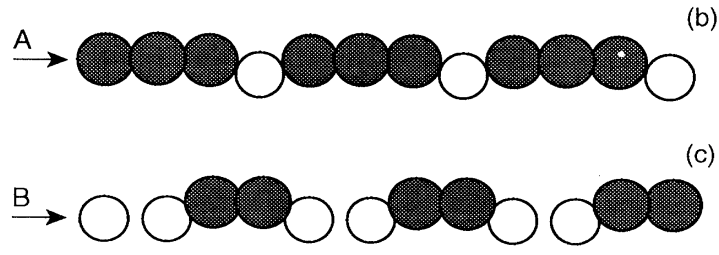

FIG. 4. (a) The calculated equilibrium vacancy stabilized dimer-trimer chain structure with four adjacent columns of substituted $\mathrm{Au}$. In (b) and (c) are shown the atomic arrangements along the [001] column containing the Au trimers and dimers. Two (one) substrate $\mathrm{Ni}$ atoms are replaced by three (two) $\mathrm{Au}$ atoms (white, grey $=\mathrm{Ni}, \mathrm{Au}$ ). 
so that the interaction is negligible. Now successively move the substituted columns of Au atoms as close as possible to the dimer-trimer chain. Figure 3(b) shows the differential change in energy per $\mathrm{Au}$ atom when the first, second, third, fourth, and fifth columns are moved next to the chain. Clearly, the interaction is attractive until four columns of substituted $\mathrm{Au}$ atoms are moved to the dimer-trimer chain. Hereafter the interaction is strongly repulsive.

The model calculation suggests that the dimer-trimer plus vacancy chains with two columns of substituted Au atoms on each side are the stable building blocks for the new structure observed. At saturation, this structure corresponds to a $(6 \times 3)$ structure with a $\mathrm{Au}$ coverage of $0.94 \mathrm{ML}$ and a ratio $\left(\theta_{\mathrm{Au}}^{\text {chain }} / \theta_{\mathrm{Au}}^{\text {alloy }}\right)$ of 0.42 . The experimentally observed $(5 \times 3)$ structure with a saturation coverage of $0.93 \mathrm{ML}$ and a ratio of $0.58 \pm 0.03$ [Fig. 2(c)] can be obtained by a slight modification of the model. If one assumes that only three and not four columns of substituted $\mathrm{Au}$ atoms are stable next to the chains, the model gives a maximum coverage of 0.93 and a ratio of $5 / 9=$ 0.56 . Given the approximate nature of the calculation and the small energies involved, this is very reasonable.

The energy per Au atom in the stable dimer-trimer plus vacancy structure with adjacent substituted $\mathrm{Au}$ atoms is calculated to be $0.070 \mathrm{eV}$ relative to a single substituted $\mathrm{Au}$ atom. In Fig. 3(a) we include this energy which shows that chain-chain interactions are very weak. The chain structure is therefore the most stable configuration at coverages high enough that the stress energy in the surface layer exceeds this energy. As seen in Fig. 3(a), the model calculation gives a critical coverage of $0.8 \mathrm{ML}$. The observed critical coverage of $0.4 \mathrm{ML}$ can be obtained in the same physical picture by imagining a somewhat larger stress in the first layer and/or by assuming a smaller energy of the stable chain structure. Again, this is not unreasonable considering the small energy differences involved.

The repulsive interaction between the chains and substituted $\mathrm{Au}$ atoms outside the stable units has one further interesting consequence of direct importance for the understanding of the first-order-like nature of the observed transition. The repulsion is of the same magnitude as the repulsion between the substituted Au atoms (Fig. 3). This means that when the critical coverage, where the chains are more stable than the substituted state, is reached, all surface Au will transform into the new phase. If something was left as substituted Au outside the region around the chains, it would feel a repulsion from the chains already formed. When the coverage is increased, more and more of the chain structures including the substituted Au atoms around them are formed. The ratio between chain atoms and substituted Au atoms therefore stays constant, as observed experimentally. In principle one could imagine that the system could phase separate into (dense) chain regions and regions with substituted atoms, because here the repulsion between the two phases would be small [10]. The long range nature of the elastic interaction between the two phases would, however, make it hard to nucleate pure phases that are stable, and we expect that this may be the reason why the surface always appears rather homogeneous and phase separation is not observed (cf. Fig. 1).

The Center for Atomic-Scale Materials Physics is funded by the Danish National Research Foundation. Further funding has been obtained from the Danish Research Councils through the Center for Nano-Tribology.

[1] S. Rousset, S. Chiang, D. E. Fowler, and D. D. Chambliss, Phys. Rev. Lett. 69, 3200 (1992).

[2] H. Röder, R. Schuster, H. Brune, and K. Kern, Phys. Rev. Lett. 71, 2086 (1993).

[3] C. T. Chan, K. P. Bohnen, and K. M. Ho, Phys. Rev. Lett. 69, 1672 (1992).

[4] C. Stampfl, M. Scheffler, H. Over, J. Burchhardt, M. Nielsen, D. L. Adams, and W. Moritz, Phys. Rev. Lett. 69, 1532 (1992).

[5] C. Nagl, O. Haller, E. Platzgummer, M. Schmid, and P. Varga (to be published).

[6] G. L. Kellogg, Phys. Rev. Lett. 67, 216 (1991).

[7] L. Pleth Nielsen, F. Besenbacher, I. Stensgaard, E. Lægsgaard, C. Engdahl, P. Stoltze, K. W. Jacobsen, and J. K. Nørskov, Phys. Rev. Lett. 71, 754 (1993).

[8] L. Eierdal, F. Besenbacher, E. Lægsgaard, and I. Stensgaard, Surf. Sci. 312, 31 (1994). The microscope is the prototype of RASTERSCOPE 3000 from DME, Herlev, Denmark.

[9] A. G. Khachaturyan, Theory of Structural Transformations in Solids (Wiley, New York, 1983).

[10] N. C. Bartelt, T. L. Einstein, and C. Rottman, Phys. Rev. Lett. 66, 961 (1991). 

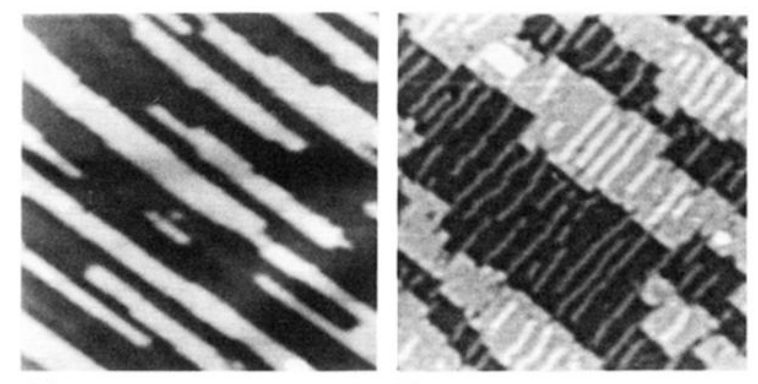

(a)

(b)
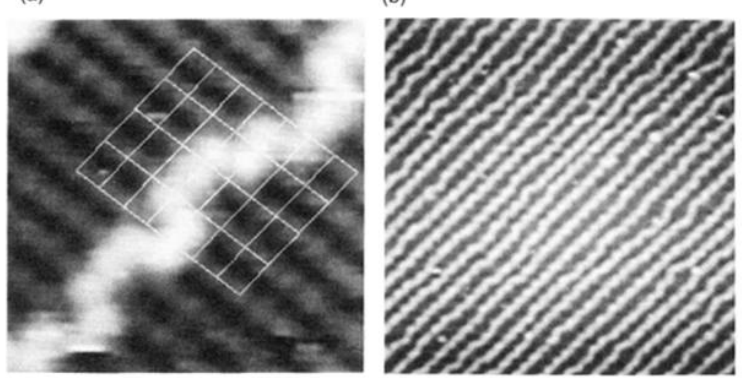

(c)

(d)

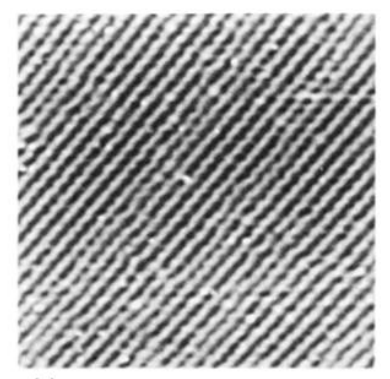

(e)

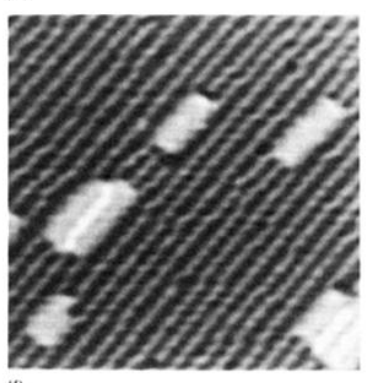

(f)

FIG. 1. (a) STM topographs showing (a) $\left(675 \times 731 \AA^{2}\right)$ the anisotropic growth of $\mathrm{Ni}$ islands $\left(\theta_{\mathrm{Au}}=0.38 \mathrm{ML}\right)$; (b) [001] directed $\mathrm{Au}$ chains $\left(480 \times 520 \AA^{2}\right.$ and $\left.\theta_{\mathrm{Au}}=0.52 \mathrm{ML}\right)$; (c) $\left(30 \times 30 \AA^{2}\right)$ the dimer-trimer chain structure $\left(\theta_{\mathrm{Au}}=\right.$ $0.45 \mathrm{ML})$, a $\mathrm{Ni}(1 \times 1)$ unit mesh is superimposed; (d) and (e) $\left(290 \times 315 \AA^{2}\right)$ of the chain structure at $\theta_{\mathrm{Au}}=0.7$ and $0.9 \mathrm{ML}$ (the distance between the chains is $d \sim 6.2$ and $d \sim 5$, respectively); (f) $\left(290 \times 315 \AA^{2}\right)$ a surface morphology like (d) after evaporation of an additional 0.1 ML Au. 